\title{
Rare case of broad ligament fibroid with cystic degeneration
}

\section{Anupama Hada*, Sangeeta Sen}

Department of Obstetrics and Gynaecology, R.N.T. Medical College, Udaipur, Rajasthan, India

Received: 04 July 2016

Accepted: 05 August 2016

\author{
*Correspondence: \\ Dr. Anupama Hada, \\ E-mail: anupamahada@gmail.com
}

Copyright: (c) the author(s), publisher and licensee Medip Academy. This is an open-access article distributed under the terms of the Creative Commons Attribution Non-Commercial License, which permits unrestricted non-commercial use, distribution, and reproduction in any medium, provided the original work is properly cited.

\begin{abstract}
Giant fibroids are known to arise from the uterus, although very rarely from extra-uterine sites. Among extra-uterine fibroids, broad ligament fibroids generally achieve enormous size and generally present with pressure symptom like bladder and bowel dysfunction. Cystic degeneration is a rare complication of benign fibroid, where presence of cystic changes mimics the ovarian tumor. We report a case of false broad ligament fibroid. This case is reported for its rarity and the diagnostic difficulties in differentiating ovarian tumor and benign fibroid with cystic degeneration.
\end{abstract}

Keywords: Broad ligament fibroid, Ovarian tumor, Cystic degeneration

\section{INTRODUCTION}

Leiomyoma is the commonest benign neoplasm of the uterus in females. It affects $30 \%$ of all the women of reproductive age but incidence of broad ligament fibroids less than $1 \%$. $^{1}$ It can be intra uterine/extra uterine. Extra uterine fibroids though do occur, but are not as common as uterine fibroids. Among the extra uterine fibroids, broad ligament fibroids are the most common to occur although it's overall incidence being rare. Broad ligament fibroids can be primary (true)/secondary (false). ${ }^{2}$ True broad ligament fibroid arises from tissues in the broad ligament itself, uterine vessels and ureters lie medial to the tumor. False broad ligament fibroid arises from uterus but grows laterally between the two layers of the broad ligament but retains its attachment to the uterus, uterine vessels and ureter lie lateral to the tumor. Clinically these lesions may manifest as extra-uterine pelvic masses that compress the urethra, bladder neck or ureter, producing symptoms of varying degrees of urinary outflow obstruction. On rare occasions, these tumors may present with unusual clinical manifestations or unusually large size. Because of its rarity it poses specific diagnostic difficulties causing an error in making the final diagnosis and therefore the management. These are usually confused with solid ovarian tumours. This is one such case report where an accurate diagnosis of whether it was an ovarian tumour or sub serosal fibroid could not be made clinically and ultrasonographically and the histopathology confirmed the diagnosis of broad ligament fibroid.

\section{CASE REPORT}

Our reported case was a 40 year old lady admitted on 25.6.16 with complaints of mass per abdomen and abdominal discomfort since one year. It was gradual in onset and progressive in nature with rapid increase in size for last two months. Associated with heaviness in lower abdomen, bladder and bowel disturbances like incomplete voiding. Menstrual history: irregular menses/ 4-5 days/20-60/ moderate flow/pain in abdomen during menses since two years. Obstetric history: P1 L1 normal deliveries. T/L done14 years back. On physical examination patient was afebrile and haemodynamically stable. On per abdominal examination a uniform mass of 16-18 weeks size gravid uterus which appears to be arising from the pelvis. No dilated/engorged veins and visible peristalsis. On palpation tumour is of varying consistency (soft to hard), non-tender, and mobile and 
with regular margins. Lower pole could not be reached. On per speculum examination cervix and vagina appears healthy and pushed towards left. No abnormal discharge. On per vaginum examination cervix was firm, deviated to left. Uterus was bulky, mobile and firm. And mass moves with cervical movement. Right and posterior forniceal fullness present.

\section{Investigations}

Tran's abdominal ultrasonography dated $11^{\text {th }}$ October 2013 showed a hypoechoic lesion of $7 \times 8.5 \mathrm{~cm}$ arising from right adenaxa. Probable diagnosis of subserosal fibroid or ovarian mass was given. The patient underwent some laboratory investigations including full blood picture, serum biochemistry, CA-125 which were all within normal limits.

\section{Intraoperative findings}

Intra-operatively, a $15 \times 15 \mathrm{cms}$ sized fibroid was noted in the right broad ligament. Uterus pushed to left side and posteriorly. Uterus was normal, right fallopian tube and round ligament stretched over the mass, both ovaries were normal. As the tumor was distorting the pelvic anatomy, careful dissection was done to prevent ureteric injuries. Excision of tumor with total abdominal hysterectomy and bilateral salpingo - oopheretomy was done (Figure 1). It was false broad ligament fibroid. Cut section of tumor showed grey white mass with multiple cystic areas filled with mucoid and gelatinous material. Straw coloured fluid drained out from the cut section.

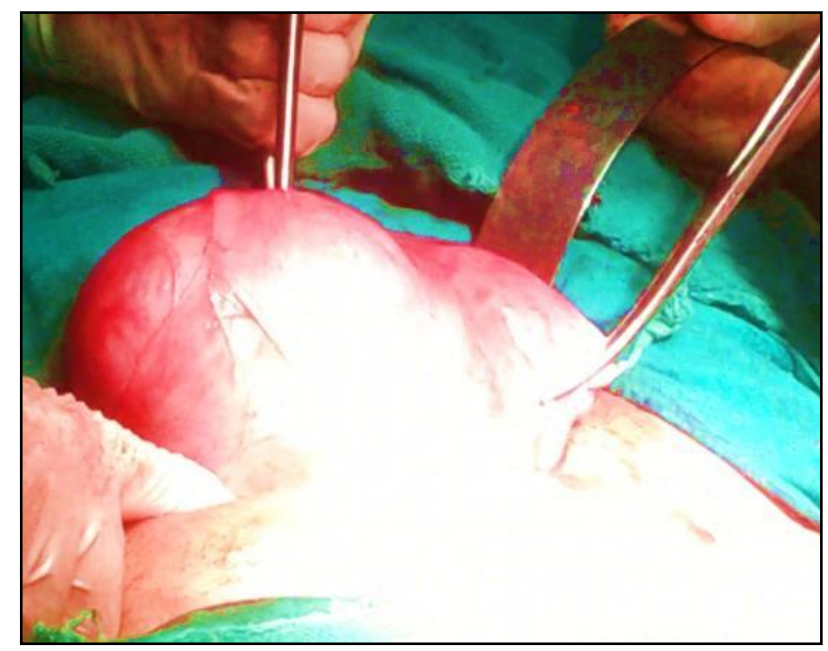

Figure 1: Excision of tumor with total abdominal hysterectomy and bilateral salpingo - oopheretomy.

\section{Histopathology}

On gross examination, single large globular soft tissue mass measuring $15 \times 15 \mathrm{cms}$. Cut section showed mucoid and cystic areas (Figure 2). Microscopic examination showed leiomyoma with cystic degeneration.
Histopathology of uterus with cervix, bilateral fallopian tubes and ovaries were unremarkable.

Postoperative period was uneventful and patient was discharged on postoperative day six.

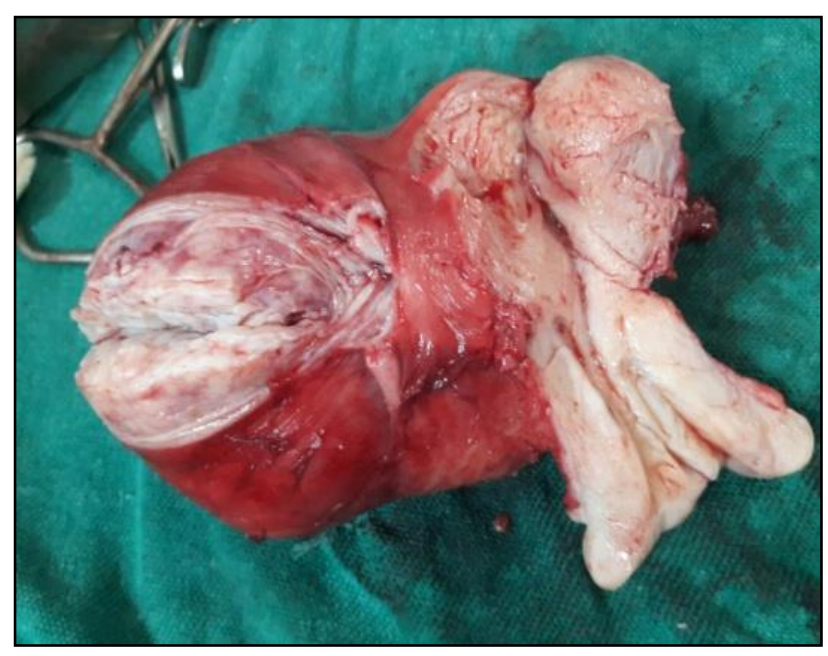

Figure 2: Cut section showed mucoid and cystic areas.

\section{DISCUSSION}

Broad ligament is a two layered peritoneal fold which connects the sides of uterus to lateral walls of pelvis and its floor. Epithelial tumors are the most common broad ligament tumors, whereas mesenchymal tumors are rare. Among the mesenchymal tumors, the most common one is leiomyoma. ${ }^{3}$ It has been suggested that leiomyomas which are adherent to broad ligament, originate from hormonally sensitive smooth muscle elements of broad ligament itself. Broad ligament leiomyoma can originate from the uterus and invade the broad ligament (false) or it can originate from broad ligament itself (true). These benign tumors are usually asymptomatic. However if the leiomyoma reaches significant size, it can push uterus to contralateral side or it can potentially compress the surrounding pelvis structure and manifest clinically with various sign and symptoms. The location of tumors often determines the various symptoms. ${ }^{4}$ It was important for any adnexal masses to discriminate between benign and malignant nature of the lesion in preoperative period for optimal patient management. The differential diagnosis for broad ligament leiomyoma includes masses from ovarian origin-benign or malignant, broad ligament cyst, lymphadenopathy and tubo-ovarian masses. In our case on clinical examination and ultrasonography it was suspicious of an ovarian tumor or subserosal fibroid. The serum level of cancer antigen CA - 125 was done which was in normal range. Leiomyomas may be single or multiple. In our case, there was a single mass in broad ligament without uterine leiomyoma. Broad ligament leiomyomas have the potential to grow to large size. ${ }^{5}$ In our case also the tumor was of large size. When they grow to a large size, secondary changes may occur. Most common secondary changes in leiomyoma are 
degeneration, infection, haemorrhage and necrosis. The cystic changes in lesion mimic the metastatic malignant ovarian tumors. ${ }^{6}$ Primary leiomyosarcoma in broad ligament is rarely reported. ${ }^{7}$

\section{ACKNOWLEDGEMENTS}

The authors would like to thankful to Head of department, R.N.T. Medical College, Udaipur for permitting to publish this case report. Also we would like to thank all the staff members of Department of Obstetrics and Gynaecology, R.N.T. Medical College, Udaipur and patient for their co-operation.

Funding: No funding sources

Conflict of interest: None declared

Ethical approval: Not required

\section{REFERENCES}

1. Kumar P, Malhotra N. Jeffcoate's Principles of Gynaecology. $7^{\text {th }}$ ed. New Delhi: Jaypee Brothers. Tumors of the corpus uteri; 2008:492.

2. Jeffcoate N. Tumors of corpus uteri. In. Batla N (ed). Jeffcoate's Principles of Gynaecology, $6^{\text {th }}$ edn. Delhi, Arnold Publication; 2001;466-497.

3. Thor AD, Young RH, Clement PB. Pathology of fallopian tube, broad ligament, peritoneum and pelvic soft tissues. Hum Pathol. 1991;22:856-67.

4. Stewart EA. Uterine Fibroids. Lancet. 2001;357:2938.

5. Godbole RR, Laksmi KS, Vasant K. Rare case of giant broad ligament fibroid with myxoid degeneration. J Scientific Society. 2012;39:144-6.

6. Rajanna DK, Pandey V, Janardhan S, Datti SN. Broad ligament fibroid mimicking as ovarian tumor on ultrasonography and computed tomography scan. J Clin Imaging Sci. 2013;3:8.

7. Duhan N, Singh S, Kadian YS, Duhan U, Rajotia N, Sangwan N. Primary leiomyosarcoma of the broad ligament: case report and review of literature. Arch Gynecol Obstet. 2009;279:705-8.

Cite this article as: Hada A, Sen S. Rare case of broad ligament fibroid with cystic degeneration. Int J Reprod Contracept Obstet Gynecol 2016;5:3226-8. 